\title{
SELECTIVE RETROGRADE LABELING OF CHOLINERGIC NEURONS WITH $\left[{ }^{3} \mathrm{H}\right]$ CHOLINE ${ }^{1}$
}

\author{
PAOLA BAGNOLI, ${ }^{2}$ ALAIN BEAUDET, ${ }^{3}$ MARIANNA STELLA, AND MICHEL CUENOD ${ }^{4}$
}

Brain Research Institute, University of Zurich, Zurich, Switzerland

\begin{abstract}
Evidence is presented which is consistent with a specific retrograde labeling of cholinergic neurons following $\left[{ }^{3} \mathrm{H}\right]$ choline application in their zone of termination. $\left[{ }^{3} \mathrm{H}\right]$ Choline injection in the rat hippocampus leads to perikaryal retrograde labeling in the ipsilateral medial septal nucleus and nucleus of the diagonal band, thus delineating an established cholinergic pathway, while only diffuse presumably anterograde labeling was observed in the lateral septum, the entorhinal cortex, and the opposite hippocampus. After $\left[{ }^{3} \mathrm{H}\right]$ choline injection in the pigeon visual Wulst, only the ipsilateral thalamic relay, of all inputs, showed similar perikaryal retrograde labeling, an observation supporting the suggestion that at least some thalamo-Wulst neurons are cholinergic.
\end{abstract}

It has been hypothesized that neuronal pathways could be characterized according to their transmitter by specific retrograde tracing. This implies selective uptake of labeled transmitters or their metabolites applied to the area of nerve termination, followed by retrograde intraaxonal migration and perikaryal retention of the labeled material. Over the last 6 years, evidence which indicates that this approach can be used for glycine, $\gamma$-aminobutyric acid (GABA), aspartate, serotonin, and catecholamines in corresponding central pathways of the rat and the pigeon has been accumulating (Hunt et al., 1975, 1976, 1977; Streit et al., 1979a, b, 1980; Streit, 1980; Cuénod and Streit, 1979; Beaudet et al., 1981; Léger et al, 1977; Araneda et al., 1980). The same principles now have been applied to the investigation of two cholinergic projections, that to the rat hippocampus and that to the pigeon Wulst, using choline as an acetylcholine (ACh) marker. (a) The septohippocampal neurons were chosen

\footnotetext{
We are very grateful to Dr. L. Wiklund for his help, to Dr. H Henke for his suggestions, and to Dr. R. Baughman for reading the manuscript. The excellent technical assistance of A. Fäh, Ch. Dudli, M Jäckli, and D. Savini is gratefully acknowledged. This work has been supported by Grants 3.636.75, 3.505.79, and 3.506.79 from the Swiss National Science Foundation and the Dr. Eric Slack-Gyr-Foundation. Dr. Alain Beaudet was supported by a centennial fellowship of the Medical Research Council of Canada and a fellowship from the Roche Foundation for Scientific Exchange.

${ }^{2}$ Present address: Istituto di Fisiologia Umana dell'Università e Istituto di Neurofisiologia del CNR, Via S. Zeno 31, I-56100 Pisa, Italy

${ }^{3}$ Present address: Laboratory of Neuroanatomy, Montreal Neurological Institute, McGill University, 3801 University Street, Montreal Quebec, Canada H3A 2B4.

"To whom correspondence should be addressed at the Brain Research Institute, University of Zürich, Postfach, CH-8029, Zürich, Switzerland.
}

as being representative of a well established cholinergic pathway on which this method could be tested reliably. The cholinergic input to the hippocampus originates in the medial septal nucleus (MS) and in the nucleus of the diagonal band (DB) and reaches its target via the fimbria. Lesions in these pathways lead to a drastic decrease in hippocampal choline acetyltransferase (ChAT) activity, ACh levels, and ACh turnover, while septal stimulation is followed by an increase in ACh hippocampal release and turnover. Other inputs to hippocampus seem to use glutamate or aspartate, serotonin, and catecholamines as transmitters (see Storm-Mathisen, 1977; Fonnum et al., 1979 for review). (b) The pigeon thalamo-Wulst projection offered the opportunity to apply the new method to a relatively unknown system as far as the transmitters are concerned. The occurrence of cholinergic terminals in the pigeon visual Wulst is suggested by a high density of quinuclidinyl benzilate binding sites and the presence of ChAT activity (Vischer et al., 1979). The ChAT activity decreases by about $40 \%$ following electrolytic lesions or kainic acid injections in the ipsilateral visual thalamic relay nucleus opticus principalis thalami (OPT), an effect which is abolished when the kainic acid injection is preceded by retinal ablation and thus degeneration of the optic nerve fibers projecting to OPT (Vischer et al., 1980; A. Vischer, P. Bagnoli, A. Csoknay, A. Burkhalter, $H$. Henke, and $M$. Cuénod, manuscript in preparation). These observations suggest that the thalamo-Wulst visual pathway consists, in part, of cholinergic neurons.

$\left[{ }^{3} \mathrm{H}\right]$ Choline was injected in the rat hippocampus or the pigeon visual Wulst and, because of the water solubility of choline and ACh, the unperfused brains were sectioned while frozen and processed according to a dry mount autoradiographic technique developed for receptor binding studies (Henke et al., 1981; Young and Kuhar, 1979). 


\section{Materials and Methods}

$\left[{ }^{3} \mathrm{H}\right]$ Choline (84 $\mathrm{Ci} / \mathrm{mmol}$, Amersham) was injected stereotaxically ( $30 \mu \mathrm{Ci}$ in $0.06 \mu \mathrm{l}, 5.95 \mathrm{~mm}$ ) either in the dorsal portion of the hippocampal complex of three male Sprague-Dawley rats (180 to $250 \mathrm{gm}$ ) or in the visual Wulst (hyperstriatum accessorium, nucleus intercalatus hyperstriati accessorii, and hyperstriatum intercalatum superior) of three pigeons (Columba livia, 350 to 400 $\mathrm{gm})$. After a survival time of $6 \mathrm{hr}$, the animals were sacrificed by decapitation, and the brains were removed rapidly in the cold and frozen in 2-methylbutane cooled to $-40^{\circ} \mathrm{C}$ in dry ice. Sections were cut in a cryostat $\left(-15^{\circ} \mathrm{C}\right)$ at $20 \mu \mathrm{m}$, melted rapidly onto cold microscope glass slides, and dried quickly at $60^{\circ} \mathrm{C}$ on a hot plate. The coverslips were coated by dipping into Kodak NTB-2 emulsion and dried overnight at $40^{\circ} \mathrm{C}$. The emulsioncoated coverslips were glued to one end of the slides bearing the tissue sections. After the glue (Loctite) set, squares of Teflon were put on top of the coverslips and the assemblies were held together with binder clips. The assemblies were stored desiccated at 2 to $4^{\circ} \mathrm{C}$ for 6 weeks. After exposure, the binder clips and Teflon were removed in the dark and a thin plastic rod spacer was placed between the tissue sections and the coverslips. The autoradiograms were developed in Dektol (1:2 with water) for $1.5 \mathrm{~min}$ at $18^{\circ} \mathrm{C}$, rinsed in cold running water, and fixed in $30 \%$ sodium thiosulfate at $4^{\circ} \mathrm{C}$. After further rinsing in distilled water, the tissues were fixed in Carnoy's solution for $20 \mathrm{~min}$ and stained with cresyl violet. The spacers were removed and the coverslips were mounted with Eukitt.

In one rat and one pigeon, the brains were perfused 6 hr after the $\left[{ }^{3} \mathrm{H}\right]$ choline injection with a $5 \%$ glutaraldehyde solution; in one rat, the brain was perfused with a mixture of $2 \%$ glutaraldehyde and $1 \%$ paraformaldehyde; and then the brains from all of the animals were processed for radioautography according to standard dipping techniques.

\section{Results}

In both rat and pigeon, the autoradiograms of the $\left[{ }^{3} \mathrm{H}\right]$ choline injection site revealed densely packed silver grains covering an area relatively larger than that observed after similar $\left[{ }^{3} \mathrm{H}\right] \mathrm{GABA}$ or $\mathrm{D}-\left[{ }^{3} \mathrm{H}\right]$ aspartate injections.

In the rat hippocampus, the injection zone showed the following pattern: the intense labeling was more prominent over the dendritic areas than over the cell layers, mainly in the dentate gyrus, over the molecular layer, and in $\mathrm{CA}_{3-}-\mathrm{CA}_{4}$, over the striatum radiatum close to the pyramidal layer (Fig. 1B). After such injections, small circular foci of high density were detected ipsilaterally in the medial septal nucleus as well as in the nucleus of the diagonal band (Fig. 1, $C$ and $D$ ). These foci were of relatively constant size and usually centered over a perikaryon, with a halo of decreasing grain concentration expanding beyond the limits of the cell body (Fig. $1 F$ ). Five to ten such foci, superimposed over a weak diffuse reaction, were observed in each section. On the other hand, diffuse neuropile labeling was observed over the ipsilateral lateral septum and over the contralateral hippocampus, covering the dendritic regions of fascia den- tata and the strata oriens and radiatum mainly in $\mathrm{CA}_{1}$, $\mathrm{CA}_{2}$, and $\mathrm{CA}_{4}$ (Fig. $1 A$ ). The cellular layers remained relatively free of silver grains and no circular foci, as described above, were observed there. Patches of diffuse labeling also were observed in a small area over the most lateral part of the ipsilateral entorhinal cortex (Fig. $1 E$ ). These patches were of heterogeneous size and larger than the foci observed in MS or DB, similar to those seen after anterograde labeling. No foci of silver grains were observed over the brain stem nuclei locus coeruleus and raphé.

After $\left[{ }^{3} \mathrm{H}\right]$ choline injection in the pigeon visual Wulst, silver grains were ohserved in the ipsilateral nucleus dorsolateralis anterior thalami, pars magnocellularis (DLAmc), known to project to the visual Wulst (Hunt and Webster, 1972; Miceli et al., 1975, 1979; P. Bagnoli, A. Burkhalter, and M. Cuénod, manuscript in preparation). Superimposed over a diffuse thulamic labeling, many small circular foci were observed, similar to those already described in the rat (Fig. 2). Other neuronal populations projecting to the visual Wulst, either from the thalamus or from the midbrain (P. Bagnoli, A. Burkhalter, and M. Cuénod, manuscript in preparation), did not show this multifocal type of labeling, while zones known to contain terminals of Wulst neurons, like the nucleus dorsolateralis anterior thalami, pars lateralis (DLL) and the nucleus geniculatus lateralis, pars ventralis (GLv) (Karten et al., 1973; Miceli et al., 1979) were labeled diffusely without any focal accumulation of grains. In rats or pigeons perfused with glutaraldehyde with or without paraformaldehyde, the diffuse labeling was present, but no multifocal pattern was found.

\section{Discussion}

The small foci of silver grains described in the rat MS and DB and in the pigeon DLAmc could be best explained by assuming that an accumulation, in some perikarya, of radioactivity associated with a diffusible molecule. Baughman and Bader (1977), in autoradiograms of retinas incubated with $\left[{ }^{3} \mathrm{H}\right]$ choline and prepared under dry conditions, observed a similar haziness in the border of the cell labeling. Their analysis showed that the labeled products consisted of ACh, choline, and phosphorylcholine. All three compounds would be likely to diffuse out of the perikaryon when the sections were heated briefly and thawed on the glass slides, thus explaining why the concentration of the grains is not restricted to the cell body as is the case with radioactivity fixed in the tissue. In some cases, two technical factors make it difficult to assign a given grain patch to a particular neuron. First, the histological quality of the unfixed tissue is rather poor, and second, the development procedure leads occasionally to slight translocation of the emulsion relative to the brain section. If one accepts, however, that the grain foci are due to radioactivity originally restricted to neuronal perikarya, then it would follow that these perikarya were labeled by retrograde migration of material coming from the nerve terminals. Indeed, no classical anterograde labeling of these pathways ever revealed the type of multifocal pattern described here, while the foci location corresponds well to that of cells labeled retrogradely in the MS and DB after a horseradish peroxidase 

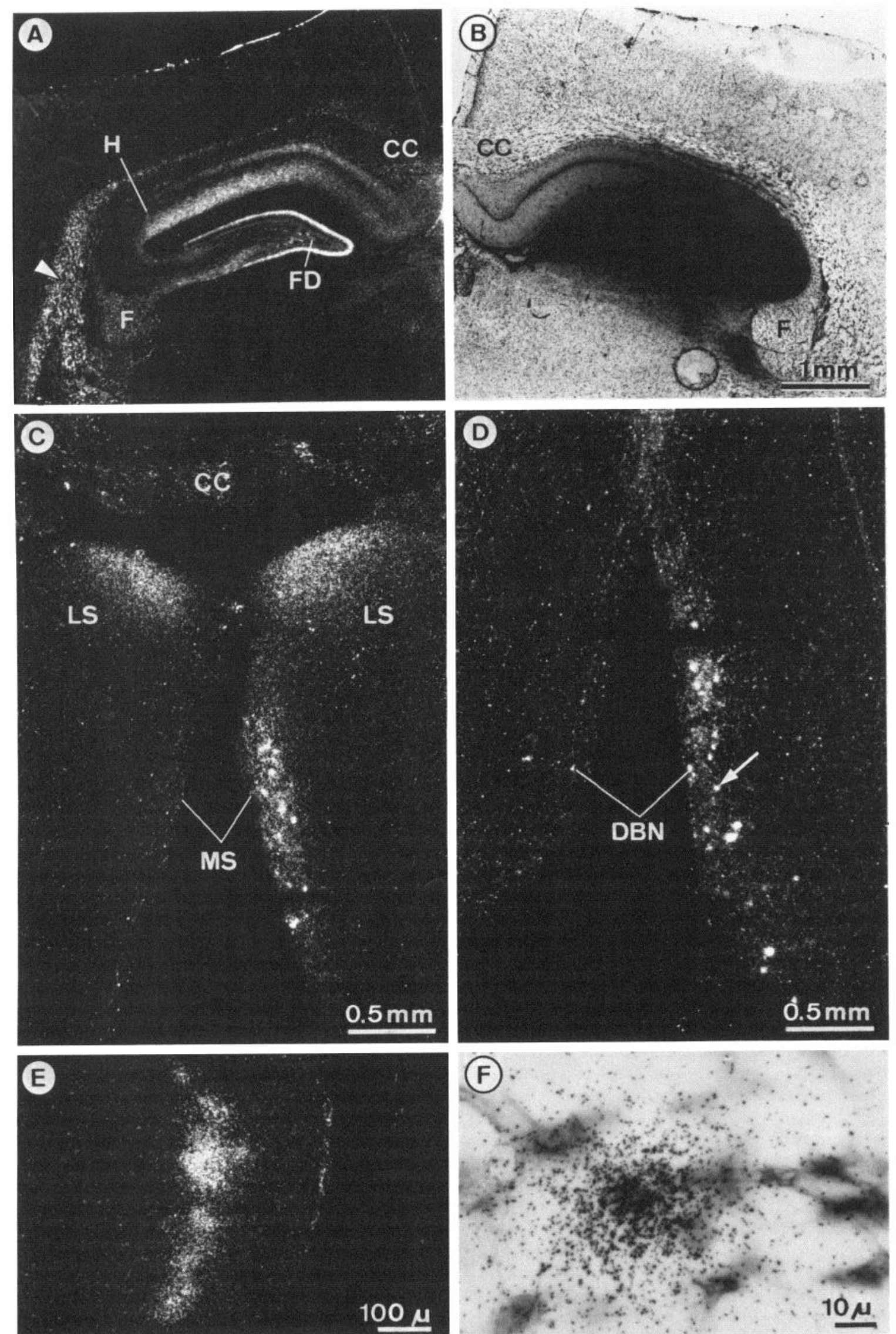

Figure 1. Autoradiograms of the rat brain $6 \mathrm{hr}$ after injection of $\left[{ }^{3} \mathrm{H}\right]$ choline $(30 \mu \mathrm{Ci})$ in hippocampus. $A$ and $B$, Hippocampal complex showing $(B)$ the injection site and $(A)$ the contralateral, diffuse labeling; note the absence of grain foci. The fibers on the left (arrowhead) are not covered by silver grains. $C$, Focal labeling in the medial septal nucleus ipsilateral to the injected hippocampus and diffuse bilateral labeling in the lateral septal area. The crack on the midline is an artifact. $D$, Focal labeling in the nucleus of the diagonal band of Broca. $E$, Diffuse labeling in the entorhinal cortex. $F$, Detail of $D($ arrow) showing one focus of grains concentric with a perikaryon. The abbreviations used are: CC, corpus callosum; DBN, diagonal band nucleus; F, fimbria hippocampi; FD, fascia dentata; H, hippocampus; LS, lateral nucleus of the septal area; MS, medial nucleus of the septal area. 

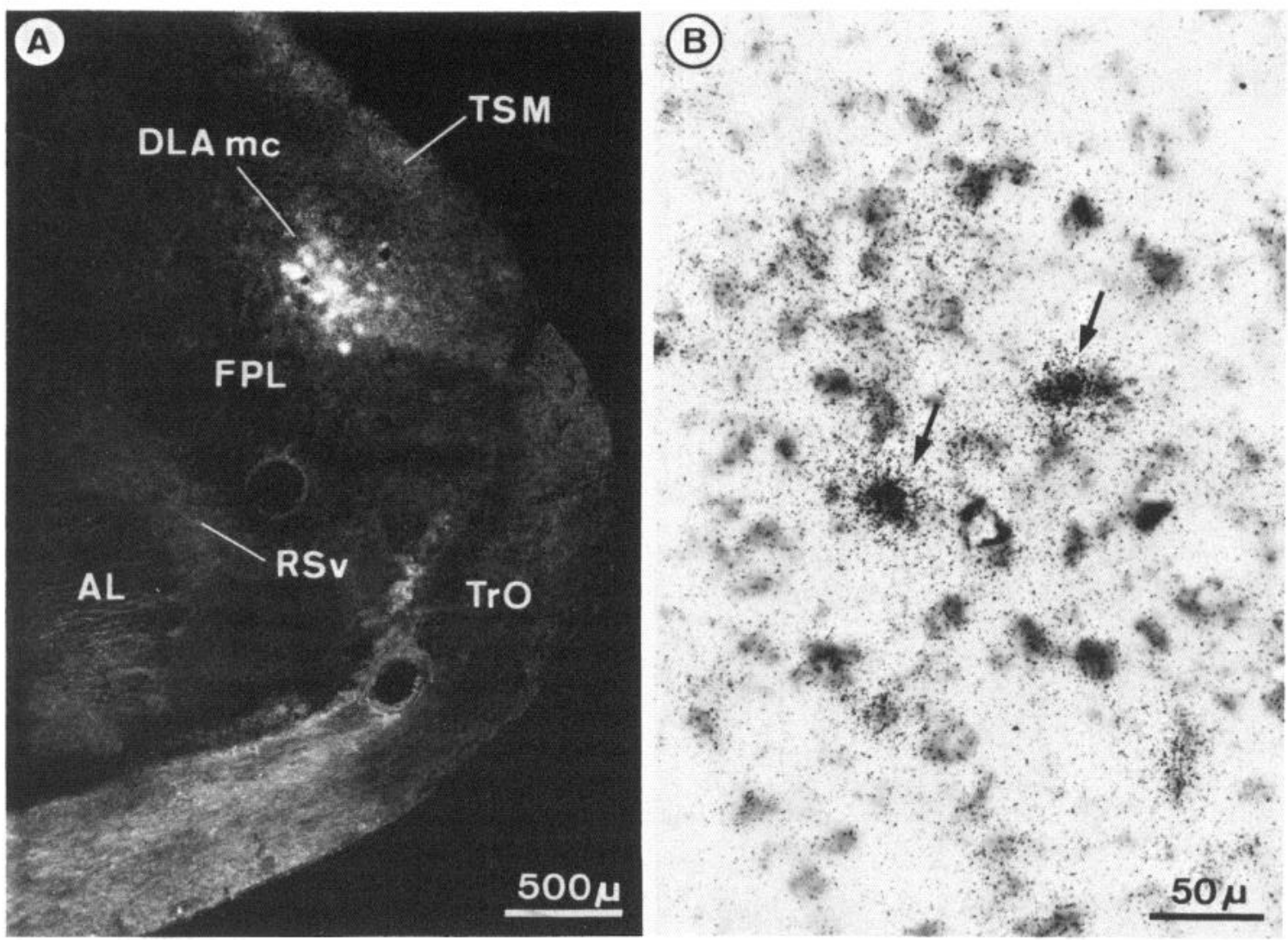

Figure 2. Autoradiograms of the pigeon brain following an injection of $\left[{ }^{3} \mathrm{H}\right]$ choline $(30 \mu \mathrm{Ci})$ in the visual Wulst. $A$, Ipsilateral thalamic area containing labeled perikarya in DLAmc, as showed in detail in $B$ (arrows). The abbreviations used are: AL, ansa lenticularis; DLAmc, nucleus dorsolateralis anterior thalami, pars magnocellularis; FPL, fasciculus prosencephali lateralis; RSv, nucleus reticularis superior, pars ventralis; TrO, tractus opticus; TSM, tractus septomesencephalicus.

(HRP) hippocampal injection (Segal and Landis, 1974) or in DLAmc after HRP application to the Wulst (Miceli et al., 1975, 1979; P. Bagnoli, A. Burkhalter, and M. Cuénod, manuscript in preparation).

The diffuse labeling observed in the rat lateral septum, contralateral hippocampus, or entorhinal cortex and in the pigeon DLL and GLv is likely to represent radioactivity transported anterogradely in neurons efferent relative to the injection sites and labeled by $\left[{ }^{3} \mathrm{H}\right]$ choline in a nonselective manner. The patterns of diffuse labeling observed after $\left[{ }^{3} \mathrm{H}\right]$ choline injections in these areas are very similar to those seen following $\left[{ }^{3} \mathrm{H}\right]$ proline or $\left[{ }^{3} \mathrm{H}\right]$ leucine injections or degeneration (Gottlieb and Cowan, 1973; Karten et al., 1973; Miceli et al., 1979; Swanson and Cowan, 1977). The case of the entorhinal cortex raises a special problem. The silver grains were grouped in patches which bear some similarity to the foci described in the septum; however, they are larger and more similar to those observed after hippocampal injections of $\left[{ }^{3} \mathrm{H}\right]-$ proline leading to anterograde transport of labeled proteins (W. M. Cowan, personal communication). Furthermore, this labeling persisted after fixation of the tissue, while the septal foci did not. Thus, it is likely that the pattern of labeling observed over the entorhinal cortex is the result of nonselective anterograde migration of the radioactivity. The different chemical nature of the radioactive material leading to diffuse labeling on one hand and to multifocal patterns on the other is suggested by the observation that glutaraldehyde fixation retained the first and not the second. The radioactivity that migrates away from the cell bodies in an unselective manner thus is incorporated in nondiffusible molecules, possibly lipids (Droz et al., 1978, 1979).

The pattern of multifocal labeling described here after $\left[{ }^{3} \mathrm{H}\right]$ choline injection is consistent with the proposal that cholinergic neurons have been labeled selectively. In the rat, the MS and DB, which both show perikaryal labeling, are at the origin of a well established cholinergic hippocampal projection (Storm-Mathisen, 1977; Fonnum et al., 1979). In contrast, the contralateral hippocampus, which gives rise to the commissural input, and the entorhinal cortex, which is at the origin of the perforant path input, both of which might use glutamate and/or aspartate as transmitters, did not present any focal labeling. Neither the serotonergic input from the raphe nucleus nor the noradrenergic input from the locus coeruleus showed any retrograde labeling. Thus, the pattern of multifocal labeling following hippocampal injections of $\left[{ }^{3} \mathrm{H}\right]$ choline appears highly selective and correlates well with the established cholinergic projections. In the pigeon, the fact that, of all of the known inputs to the visual Wulst, perikaryal labeling was only present in the DLAmc favors the selectivity of the retrograde labeling and supports the proposal that the thalamo-Wulst visual pathway contains cholinergic neurons.

In the present case, as with other transmitters that 
lend themselves to selective retrograde tracing, the specificity could rely on uptake systems. A specific high affinity uptake is well documented for choline and has been characterized biochemically (Yamamura and Snyder, 1973; Baughman and Bader, 1977; Dowdall et al., 1976; Jope, 1979; Whittaker and Dowdall, 1975). Moreover, the fact that, even after the injection of a high concentration of $\left[{ }^{3} \mathrm{H}\right]$ choline, silver grains were restricted to putative cholinergic perikarya suggests that the selectivity of the retrograde labeling could rest not only on the uptake but also on the transport. In contrast, the anterograde migration of the label was unselective, indicating that choline was entering other types of neurons.

In conclusion, although more work is needed in order to establish the role of the time course in relation to the length of the pathways and to define its limitations, the present method should prove a powerful one for tracing cholinergic pathways in the central nervous system.

\section{References}

Araneda, S., H. Gamrani, C. Font, A. Calas, J. F. Pujol, and P. Bobillier (1980) Retrograde axonal transport following injection of $\left[{ }^{3} \mathrm{H}\right]$-serotonin into the olfactory bulb. II. Radioautographic study. Brain Res. 186: 417-427.

Baughman, R. W., and C. R. Bader (1977) Biochemical characterization of the cholinergic system in the chicken retina. Brain Res. 138: 469-485.

Beaudet, A., A. Burkhalter, J. C. Reubi, and M. Cuénod (1981) Selective bidirectional transport of $\left[{ }^{3} \mathrm{H}\right]-\mathrm{D}$-aspartate in the pigeon retinotectal pathway. Neuroscience, in press.

Cuénod, M., and P. Streit (1979) Amino acid transmitters and local circuitry in optic tectum. In The Neurosciences: Fourth Study Program, F. O. Schmitt and F. G. Warden, eds., pp. 989-1004, MIT Press, Cambridge, MA.

Dowdall, M. J., G. Fox, K. Wachtler, V. P. Whittaker, and H. Zimmerman (1976) Recent studies on the comparative biochemistry of the cholinergic neuron. Cold Spring Harbor Symp. Quant. Biol. 40: 65-81.

Droz, B., L. Di Giamberardino, H. L. Koenig, J. Boyenval, and R. Hassig (1978) Axon-myelin transfer of phospholipid components in the course of their axonal transport as visualized by radioautography. Brain Res. 155: 347-353.

Droz, B., M. Brunetti, L. Di Giamberardino, H. L. Koenig, and G. Porcellati (1979) Transfer of phospholipid constituents to glia during axonal transport. Soc. Neurosci. Symp. 4: 344360 .

Fonnum, F., R. Lund Karlsen, D. Malthe-Sørenssen, K. K. Skrede, and I. Walaas (1979) Localization of neurotransmitters, particularly glutamate, in hippocampus, septum, nucleus accumbens and superior colliculus. In Development and Chemical Specificity of Neurons: Progress in Brain Research, M. Cuénod, G. Kreutzberg, and F. Bloom, eds., pp. 167-191, Elsevier, Amsterdam.

Gottlieb, D. I., and W. M. Cowan (1973) Autoradiographic studies of the commissural and ipsilateral association connections of the hippocampus and dentate gyrus of the rat. I. The commissural connections. J. Comp. Neurol. 149: 393-422.

Henke, H., A. Beaudet, and M. Cuénod (1981) Autoradiographic localization of specific kainic acid binding sites in pigeon and rat cerebellum. Brain Res., in press.

Hunt, S. P., and K. E. Webster (1972) Thalamo-hyperstriate interrelations in the pigeon. Brain Res. 44: 647-652.

Hunt, S. P., H. Künzle, and M. Cuénod (1975) The retrograde transport of amino acids and a glycinergic system within the optic lobe. Exp. Brain Res. S23: 189.

Hunt, S. P., H. Henke, H. Künzle, J. C. Reubi, T. Schenker, P. Streit, D. Felix, and M. Cuénod (1976) Biochemical neuroa- natomy of the pigeon optic tectum. In Afferent and Intrinsic Organization of Laminated Structures in the Brain: Experimental Brain Research Supplement 1, O. Creutzfeldt, ed., pp. 521-525, Springer-Verlag, New York.

Hunt, S. P., P. Streit, H. Künzle, and M. Cuénod (1977) Characterization of the pigeon isthmo-tectal pathway by selective uptake and retrograde movement of radioactive compounds and by Golgi-like HRP. Brain Res. 129: 197-212.

Jope, R. S. (1979) High affinity choline transport and acetylCoA production in brain and their roles in the regulation of acetylcholine synthesis. Brain Res. Rev. 1: 313-345.

Karten, H. J., W. Hodos, W. J. Nauta, and A. M. Revzin (1973) Neural connections of the visual Wulst of the avian telencephalon: Experimental studies in the pigeon (Columba. livia) and owl (Speotyto canicularia). J. Comp. Neurol. 150: 253-276.

Léger, L., J. F. Pujol, P. Bobillier, and M. Jouvet (1977) Transport axoplasmique de la sérotonine par voie retrograde dans les neurones monoaminergiques centraux. C. R. Acad. Sci. (D) (Paris) 285: 1179-1182.

Miceli, D., J. Peyrichoux, and J. Repérant (1975) The retinothalamo-hyperstriatal pathway in the pigeon (Columba livia). Brain Res. 100: 125-131.

Miceli, D., H. Gioanni, J. Repérant, and J. Peyrichoux (1979) The avian visual Wulst: I. An anatomical study of afferent and efferent pathways. II. An electrophysiological study of the functional properties of single neurons. In Neural Mechanisms of Behavior in the Pigeon, A. M. Granda and J. H. Maxwell, eds., pp. 223-254, Plenum Press, New York.

Segal, M., and S. Landis (1974) Afferents to the hippocampus of the rat studied with the method of retrograde transport of horseradish peroxidase. Brain Res. 78: 1-15.

Storm-Mathisen, J. (1977) Localization of transmitter candidates in the brain: The hippocampal formation as a model. Prog. Neurobiol. 8: 119-181.

Streit, P. (1980) Selective retrograde labeling indicating the transmitter of neuronal pathways. J. Comp. Neurol. 191:429463.

Streit, P., E. Knecht, and M. Cuénod (1979a) Transmitterspecific retrograde labeling in the striato-nigral and raphénigral pathways. Science 205: 306-308.

Streit, P., J. C. Reubi, M. Wolfensberger, H. Henke, and M. Cuénod (1979b) Transmitter-specific retrograde tracing of pathways? In Development and Chemical Specificity of Neurons: Progress in Brain Research, M. Cuénod, G. Kreutzberg, and F. Bloom, eds., pp. 489-496, Elsevier, Amsterdam.

Streit, P., E. Knecht, and M. Cuénod (1980) Transmitter related retrograde labeling in the pigeon optic lobe: $A$ high resolution autoradiographic study. Brain Res. 187: 59-67.

Swanson, L. W., and W. M. Cowan (1977) An autoradiographic study of the organization of the efferent connections of the hippocampal formation in the rat. J. Comp. Neurol. 172: 4984.

Vischer, A., H. Henke, and M. Cuénod (1979) Enzyme and binding assays in 4 regions of pigeon brain. Experientia 35: 928.

Vischer, A., A. Fäh, A. Burkhalter, and H. Henke (1980) Kainic acid toxicity in the pigeon thalamus and consequent decrease in the hyperstriatal choline acetyltransferase and glutamic acid decarboxylase. Experientia 36: 703.

Whittaker, V. P., and M. J. Dowdall (1975) Current state of research on cholinergic synapses. In Cholinergic Mechanisms, P. G. Waser, ed., pp. 35-40, Raven Press, New York.

Yamamura, H. I., and S. H. Snyder (1973) High affinity transport of choline into synaptosomes of rat brain. J. Neurochem. 21: 1355-1374.

Young, S. W., III, and M. J. Kuhar (1979) A new method for receptor autoradiography: $\left[{ }^{3} \mathrm{H}\right]$ opioid receptors in rat brain. Brain Res. 179: 255-270. 